\title{
ОТКРЫТАЯ И ПРИНУДИТЕЛЬНАЯ ЛИЦЕНЗИЯ КАК СПОСОБЫ СОБЛЮДЕНИЯ ПРИНЦИПА БАЛАНСА ИНТЕРЕСОВ
}

\section{OPEN AND COMPULSORY LICENSES AS WAYS TO COMPLY WITH THE PRINCIPLE OF BALANCE OF INTERESTS}

\section{A. Mironova}

Summary. The article deals with the provisions concerning the institutions of open and compulsory licenses as ways of using and distributing a patented object. The key terms and conditions of granting an open and compulsory license are described, and controversial issues of applying a compulsory license are considered. The author comes to the conclusion that the institution of licensing as a way to maintain a balance between the interests of the patent owner and the society has shortcomings: the compulsory license is sought to be used as a tool to influence the patent owner with a clear violation of the interests of the latter, while the open license is granted by the copyright holder in an effort to avoid the use of a compulsory license.

Keywords: open license, compulsory license, patent owner, result of intellectual activity, exclusive rights, patent.
Миронова Александра Игоревна

Старший преподаватель, Академия труда и социальных отношений (2. Москва); соискатель, Российский государственный университет правосудия

(2. Москва)

alexsandra_mironova@mail.ru

Аннотация. В статье рассмотрены положения, касающиеся институтов открытой и принудительной лицензии, как способов использования и распространения запатентованного объекта. Дана характеристика ключевых положений и условий предоставления открытой и принудительной лицензии, рассмотрены спорные вопросы применения принудительной лицензии. Автор приходит к выводу о том, что институт лицензирования как способ сохранения баланса интересов патентообладателя и общества имеет недоработки: принудительную лицензию стремятся использовать как инструмент воздействия на патентообладателя с явным нарушением интересов последнего, в то время как открытую лицензию правообладатель предоставляет в стремлении избежать использования принудительной лицензии.

Ключевые слова: открытая лицензия, принудительная лицензия, патентообладатель, результат интеллектуальной деятельности, исключительные права, патент.

С одной стороны, правообладатель заинтересован в получении определенных выгод от своего изобретения. Он стремится к тому, чтобы о результатах интеллектуальной деятельности узнало как можно больше людей, что благоприятно сказывается на его репутации и повышении лояльности потребителей к другим продуктам, что в дальнейшем повышает доход патентообладателя. С другой - государство стремится к тому, чтобы в некоторых случаях результат интеллектуальной деятельности получил большое распространение, особенно это касается фармацевтической сферы. При этом может возникнуть ситуация, когда правообладатель не заинтересован в дальнейшем использовании охраняемого объекта либо не обладает достаточным количеством ресурсов для внедрения запатентованного объекта в экономический оборот, либо его не устраивают условия лицензии, на которых ему предлагается использование запатентованного объекта. Однако внедрить изобретение необходимо.

Соответственно, ему (патентообладателю) приходится выбирать: либо позволить использовать изобретение любому заинтересованному лицу, либо ждать, когда за- 
интересованное лицо получит лицензию на основании решения суда, и до тех пор не использовать изобретение. Таким образом, при достаточном количестве вариантов патентообладатель в любом случае рискует нарушить баланс интересов. Законодатель предлагает на выбор два способа решения проблемы сохранения баланса интересов патентообладателя и общества: открытая и принудительная лицензии, и если открытую лицензию рассматривают как добровольное ограничение исключительных прав держателя патента, то принудительную - как штрафную санкцию или инструмент ограничения монополии для соблюдения честной конкуренции, что особенно ярко демонстрирует ситуация на фармацевтическом рынке России.

Анализируя институт открытой лицензии, можно сказать, что ряд авторов, в частности Л.П. Пискун, считают, что открытая лицензия - это не разновидность лицензионного договора, а публичная оферта [13, с. 46]. Под открытой лицензией в данном случае понимается публичное заявление патентообладателя предоставить любому лицу право на использование изобретения. Указывая в заявлении все существенные условия договора, патентообладатель выражает готовность заключить договор с любым субъектом, и обязан заключить его при наличии согласия на заключение контрагента. Иными словами, правоотношения, связанные с открытой лицензией, полностью подходят под определение публичной оферты, установленное п. 2 ст. 437 ГК РФ.

Анализ института открытой лицензии позволяет говорить о свободе воли патентообладателя, в то же время, анализируя принудительную лицензию, правильнее подразумевать санкцию по отношению к нему. Пунктами 2-4 ст. 5.А Парижской конвенции установлены нормы, направленные на предупреждение злоупотребления исключительным правом, что обусловлено соблюдением принципа баланса интересов. Патентообладатель может как полностью не использовать РИД, так и использовать его недостаточно. При этом «недостаточность»понятие субъективное, не имеющее четких критериев. По своему усмотрению договаривающиеся государства могут принимать и иные меры. В частности, подобные случаи могут распространиться на патенты, «затрагивающие жизненные интересы страны в вопросах ее безопасности или здравоохранения, так называемые зависимые патенты» [1].

Принудительную лицензию могут истребовать в отношении изобретений, полезных моделей, промышленных образцов и селекционных достижений. Условием истребования принудительной лицензии выступает неиспользование или недостаточное использование патентообладателем изобретения или промышленного образца в течение четырех лет со дня выдачи патента, а полезной модели - в течение трех лет. Не используя изобретение, патентообладатель создает дефицит товара или услуги, что, в свою очередь, может повлечь угрозу общественным интересам. В связи с этим законодатель предусмотрел возможность получения принудительной лицензии по решению суда, если истец, желая заключить лицензионный договор на использование РИД, получил отказ от патентообладателя.

Принудительную лицензию можно получить не на всю интеллектуальную собственность. Так, профессор Г.Н. Черничкина отмечает, что заинтересованное лицо не может заключить лицензионный договор в обязательном порядке, если объектом соглашения выступают произведения и объекты смежных прав, средства индивидуализации, топология интегральные микросхемы и ноу-хау. Это связано с тем, что первостепенная задача произведений заключается не в получении экономической выгоды, а в удовлетворении эстетических потребностей. Соответственно, нельзя принудить автора к заключению лицензионного договора, если он не хочет вводить свое произведение в экономический оборот [16, с. 72-82]. Результаты интеллектуальной деятельности, в отношении которых может быть заключен лицензионный договор в порядке открытой лицензии, несколько шире, чем в порядке принудительной лицензии, так как для выдачи последней предусмотрены более жесткие условия.

При рассмотрении открытой и принудительной лицензии нельзя не уделить внимания условиям данных договоров. В случае с открытой лицензией предполагается, что патентообладатель предлагает заключить договор на использование РИД абсолютно любому лицу, заинтересованному в этом и принимающему условия использования РИД в рамках открытой лицензии. Принимая оферту, заинтересованный субъект подтверждает свое согласие на заключение договора на условиях патентообладателя.

Открытая лицензия позволяет любому субъекту использовать РИД, если правообладатель ранее заявил в Роспатент о своем желании предоставить открытую лицензию на свое изобретение в соответствии с Правилами подачи и рассмотрения заявления патентообладателя о предоставлении права на открытую лицензию и публикации сведений о таком заявлении [5]. Только наличие согласия правообладателя в форме заявления в уполномоченный орган дает лицу право обратиться за заключением лицензионного договора. Такой договор заключается на условиях, указанных правообладателем в заявлении. Однако заключение лицензионного договора в условии открытой лицензии является обязанностью, а не правом правообладателя. 
Профессор Э.П. Гаврилов рассматривает принудительную лицензию как гражданско-правовой договор с обязательным для одной из сторон заключением [8, с. 56]. С Э.П. Гавриловым необходимо согласиться, но в части рассмотрения принудительной лицензии как гражданского договора, выступающего только лишь в качестве результата возникших спорных правоотношений. В то же время профессор Г.Н. Черничкина считает, что принудительную лицензию относят к договорам, заключаемым в обязательном порядке только по тому основанию, что этот договор заключается на основе решения суда [15, с. 286]. Поскольку понятие договора предполагает волю сторон, а в случае принудительной лицензии патентообладатель явно не заинтересован в заключении такого договора, например, из соображений конкуренции. Соответственно, принудительная лицензия санкция по отношению к патентообладателю.

При отсутствии согласия правообладателя на заключение лицензионного договора законодателем предусмотрена возможность обратиться за выдачей принудительной лицензии при наличии определенных условий (ст. ст. 1362 и 1463 ГК РФ). Первоначальным и главным основанием является отказ правообладателя от заключения лицензионного договора. Причинами такого отказа могут быть невозможность использования или невозможность получения прибыли при использовании РИД лицом, желающим заключить лицензионный договор.

Согласно п. 2 ст. 1362 ГК РФ, возможно предоставление принудительной лицензии, ели заявитель докажет, что его РИД имеет существенные экономические преимущества перед РИД более раннего патента на подобное изобретение, что активно используется отечественными фармацевтическими компаниями для получения лицензии на производство аналогов зарубежных препаратов. Суд зачастую удовлетворяет их требования, руководствуясь принципом приоритета здоровья граждан. Однако справедливо оценить существенные экономические преимущества российского аналога перед зарубежным препаратом непросто, так как существенность базируется на более низкой стоимости российского препарата для потребителя. Тем не менее, на практике разница в цене не значительна, а качество отечественной продукции ниже, чем оригинального препарата.

Можно предположить, что предоставление принудительных лицензий экономически выгодно государству, так как по условиям лицензионного договора лицензиар получает компенсацию за использование лицензии, которая соизмеримо ниже возможной прибыли, получаемой при продаже РИД патентообладателем от своего имени, а государственный контракт на производство препарата заключается по минимальным ценам, что, в свою очередь, ставит под сомнение выгоду лицензиата. Таким образом, имеет место нарушение интересов не только патентообладателя, но и потребителей, и получателя принудительной лицензии.

Для открытой лицензии, равно как и для принудительной лицензии характерно то, что любое лицо может получить лицензию на использование РИД, если оно готово использовать изобретение. Основанием же открытой лицензии является оферта, а основанием принудительной лицензии - неисполнение патентообладателем своей обязанности использовать запатентованный РИД. Однако основополагающим условием заключения лицензионного договора является волеизъявление правообладателя. Патентообладатель сообщает в уполномоченный орган федеральной исполнительной власти условия использования РИД, которые публикуются за счет патентообладателя в открытом бюллетене Роспатента [4]. Если появляются желающие использовать изобретение, то с ними патентообладатель заключает договор на условиях простой лицензии.

Принудительная лицензия может быть истребована лицом, желающим заключить лицензионный договор, только, если имеют место одновременно несколько условий: правообладатель отказался заключить лицензионный договор; правообладатель не использует/недостаточно использует объект; срок, в течение которого правообладатель допустил неиспользование; действия правообладателя привели к понижению предложения на рынке; лицо, желающее заключить лицензионный договор, имеет необходимость и возможность использования объекта.

Нельзя не согласиться с профессором Г.Н. Черничкиной, которая справедливо замечает, что принудительная лицензия - это санкция, применяемая к патентообладателю, который не исполняет свою обязанность по использованию принадлежащего ему результата, хотя положения ст. 1239 ГК РФ характеризуют принудительную лицензию как договор, заключенный по решению суда [16, с. 72-82].Аналогичного мнения придерживается и В.И. Еременко, который полагает, что принудительная лицензия носит ярко выраженный штрафной характер [10, с. 28-34].

Согласно абз. 3 п. 1 ст. 1362 ГК РФ, суд может прекратить действие принудительной лицензии по иску патентообладателя, если изменятся или перестанут существовать обстоятельства, послужившие причиной предоставления указанной лицензии. Например, принудительную лицензию следует прекратить, если патентообладатель сам начал использовать РИД, наладив производство и реализацию товаров или услуг, обеспечивая потребность рынка $[11$, с. 15]. Однако при этом 
Таблица 1. Количество поступивших и опубликованных заявлений о предоставлении открытой лицензии за 2016-2020 гг. [9]

\begin{tabular}{|l|l|l|l|l|l|}
\hline Год & $\mathbf{2 0 1 6}$ & $\mathbf{2 0 1 7}$ & $\mathbf{2 0 1 8}$ & $\mathbf{2 0 1 9}$ & $\mathbf{2 0 2 0}$ \\
\hline $\begin{array}{l}\text { Количество поступивших } \\
\text { заявлений }\end{array}$ & 82 & 80 & 89 & 104 & 197 \\
\hline $\begin{array}{l}\text { Количество } \\
\text { опубликованных } \\
\text { заявлений }\end{array}$ & 95 & 106 & 108 & 111 & 200 \\
\hline
\end{tabular}

становится ненадежным положение лицензиата. То есть в любой момент право лицензиата на использование запатентованного объекта может быть прекращено, но он уже к тому времени может вложить в производство и распространение товара часть своих ресурсов. При предоставлении открытой лицензии договор может быть расторгнут только в том случае, если он (лицензиат) нарушает условия использования запатентованного объекта. При принятии же судом решения о предоставлении принудительной лицензии не предусмотрено наличие положений, защищающих лицензиата в дальнейшем при прекращении данной лицензии.

Патентообладатель может прекратить оферту открытой лицензии. Для этого необходимо, чтобы в течение двух лет со дня публикации сведений об открытой лицензии патентообладатель не получил ни одного предложения о заключении лицензионного договора на озвученных им условиях. Однако прекращение оферты подразумевает также и то, что патентообладателю необходимо доплатить патентную пошлину за поддержание патента в силе. Пошлина доплачивается за период, прошедший со дня публикации сведений об открытой лицензии, а в дальнейшем - уплачивается в полном размере.

Так как лицензионный договор подразумевает использование лицензиатом предмета договора - РИД, логично, что при условии выплаты вознаграждения учитывается предполагаемый доход лицензиата. Вознаграждение может быть как в фиксированной сумме, так и в процентном исчислении от дохода (выручки), а также в смешанной форме (часть вознаграждения - фиксированная, часть - в процентном исчислении). Рассматривая последний вариант, логично предположить, что при неиспользовании РИД, приобретатель может нарушать условие договора о выплате процентов от дохода. Пленум Верховного Суда РФ в своем постановлении от 23 апреля 2019 г. № 10 «О применении части четвертой ГК РФ» [6] говорит, что при неиспользовании результата лицензиат имеет право на выплату только фиксированной части вознаграждения. Однако такая ситуация позволяет патентообладателю требовать расторжения договора и возмещения убытков. Такое же право у лицензиара появляется, если размер вознаграждения предусматривает только процентное исчисление от дохода лицензиата при использовании РИД [7, с. 128].

В ситуации с вознаграждением при предоставлении принудительной лицензии довольно сложно найти компромисс между указанным в решении суда вознаграждением и устраивающим лицензиара. Как правило, одним из факторов предоставления принудительной лицензии является желание сократить бюджетные расходы на приобретение и распространение результата. Соответственно, и размер вознаграждения, получаемого лицензиаром по условиям принудительной лицензии, зачастую не является сравнимым с суммой дохода, получаемого лицензиаром при распространении результата от своего имени.

Согласно официальным сведениям, представленным Роспатентом [9], в 2020 году опубликовано 200 заявлений о предоставлении открытой лицензии, что почти в 2 раза больше, чем в 2019 году. Анализируя данные за 2016-2020 гг., представленные в таблице 1, можно говорить о положительной динамике поступивших и опубликованных заявлений.

Таким образом, можно сделать вывод о том, что повышение интереса к открытым лицензиям со стороны правообладателей говорит о том, что они (правообладатели) стремятся не только к тому, чтобы максимальное количество потребителей получили доступ к результату интеллектуальной деятельности. Можно предположить, что патентообладатели рассматривают открытую лицензию как способ компенсации недостаточного использования РИД с целью избегания принудительной лицензии, так как при ее предоставлении третьим лицам патентообладатель зачастую оказывается в более невыгодном положении, чем предоставляя право использовать патент на условиях открытой лицензии. В отношении использования механизма принудительной лицензии сложно говорить об его эффективности как средства предоставления доступа к результату интеллектуальной деятельности, так как зачастую предоставление принудительной лицензии снижает объем инвестиций, патентообладатель перестает вкладывать ресурсы в развитие производство и создание новых РИД. В конечном итоге складывается ситуация, когда ограничение прав патен- 
тообладателя негативно сказывается на ситуации в отрасли экономики: рынок наполняют некачественные аналоги, потребители не получают нужного результата, предпочитая приобретать товары других производителей. Данная ситуация нарушает также и права лицензиата.

В качестве решения сложившейся ситуации можно предложить доработку правовых основ выдачи принудительных лицензий. По нашему мнению, целесообразно установить минимальный предел вознаграждения, получаемого лицензиаром, выраженный в фиксированных цифрах или процентном эквиваленте по отношению к назначенной лицензиаром сумме. Кроме того, целесообразно упрочить положение лицензиата в случае прекращения действия принудительной лицензии, например, разработав процедуру прекращения действия лицензии, порядок выплаты и размер компенсации потраченных средств и недополученной выгоды. Такой подход станет еще одним инструментом, исключающим злоупотребление положением со стороны патентообладателя.

Таким образом, институт лицензирования как инструмент сохранения баланса интересов патентообладателя и общества недостаточно проработан, а складывающаяся экономическая ситуация позволяет предположить, что принудительную лицензию стремятся использовать не как вариант повышения использования РИД, а как инструмент воздействия на патентообладателя с явным нарушением интересов последнего, в то время как открытая лицензия используется патентообладателями в стремлении избежать использования принудительной лицензии, что не способствует развитию научно-исследовательской деятельности. Кроме того, возможность предоставления принудительной лицензии не только по решению суда может привести к злоупотреблению правом со стороны антимонопольных органов, так как ключевым фактором выдачи лицензии будет противодействие конкуренции, а не приоритет интересов общества.

\section{ЛИТЕРАТУРА}

1. Парижская Конвенция по промышленной собственности от 20.03.1883 (ред. от 02.10.1979) // Закон.— 1993.— № 7 .

2. Гражданский кодекс Российской Федерации (часть четвертая): Федеральный закон от 18.12.2006 № 230-Ф3 (ред. 0т 18.07.2019) // Собрание законодательства РФ.— 2006.— № 52 (1 ч.).—- С. 5496.

3. Гражданский кодекс Российской Федерации (часть первая) от 30.11.1994 № 51-Ф3 (ред. от 08.12.2020) // Собрание законодательства РФ.— 1994.— № 32. - Ст. 3301.

4. Приказ Министерства экономического развития РФ от 12 августа 2015 № 552: 06 утверждении Административного регламента предоставления Федеральной службой по интеллектуальной собственности государственной услуги по рассмотрению заявления правообладателя о предоставлении любому лицу права использования изобретения, полезной модели или промышленного образца (открытой лицензии), ходатайства об отзыве заявления об открытой лицензии (с изменениями на 7 июня 2017 года) [Электронный ресурс] // Официальный сайт Федеральной службы по интеллектуальной собственности (Роспатента). — Режим доступа: https://rospatent.gov.ru/ru/documents/552-prikaz-minekonomrazvitiya-rossii-ot-12-08-2015-552\#l1 (дата обращения: 13.03.2021).

5. Правила подачи и рассмотрения заявления патентообладателя о предоставлении права на открытую лицензию и публикации сведений о таком заявлении [Электронный ресурс] // Официальный сайт Федеральной службы по интеллектуальной собственности (Роспатента) — Режим доступа: https:// rospatent.gov.ru/ru/documents/pravila-podachi-i-rassmotreniya-zayavleniya-patentoobladatelya-0-predostavlenii-prava-na-otkrytuyu-licenziyu-i-publikaciisvedeniy-o-takom-zayavlenii (дата обращения: 13.03.2021).

6. Постановление Пленума Верховного Суда РФ от 23.04.2019 № 10 «0 применении части четвертой Гражданского кодекса Российской Федерации» // Российская газета.—2019.— 06 мая.—№ 96.

7. Витрянский В.В. Российское гражданское право: учебник: в 2 т. Т. 2: Обязательственное право./ В.В. Витрянский, В.С. Ем, Н.В. Козлова и др.; отВ. ред. Е.А. Суханов. 2-е изд., стереотип.-М.: Статут, 2011.- 714 с.

8. Гаврилов Э.П. Патентное право в части четвертой ГК РФ: комментарий к главе 72 /Э.П. Гаврилов // Хозяйство и право.—2016.— № 12.—C. $55-63$.

9. Годовой отчет Роспатента за 2020 год [Электронный ресурс] // Официальный сайт Федеральной службы по интеллектуальной собственности (Роспатента).—Режим доступа: https://rospatent.gov.ru/ content/uploadfiles/otchet-2020-ru.pdf (дата обращения: 13.03.2021).

10. Еременко В.И. Исключения из патентной монополии в соответствии с частью четвертой ГК РФ / В.И. Еременко // Законодательство и экономика.2008. - № 8.- - . 28-34.

11. Комментарий к части четвертой Гражданского кодекса Российской Федерации (постатейный) / под общей ред. В.В. Погуляева.— М.: Юстицинформ, 2008. - $640 \mathrm{C}$.

12. Котова М. «Фармасинтез» начал выпуск лекарства от COVID-19 в обход патентообладателя [Электронный ресурс] / M. Котова // «Ведомости» — ведущее деловое издание России. - Режим доступа: https://www.vedomosti.ru/business/articles/2021/01/24/855238-farmasintez-covid-19 (дата 0бращения: 13.03.2021).

13. Пискун Л.П. Права авторов изобретений, полезных моделей и промышленных образцов / Л.П. Пискун // ИС. Промышленная собственность.— 2020.№ 2.- C. 45-48. 
14. Черничкина Г.Н. К вопросу об общих принципах охраны интеллектуальной собственности частью 4 ГК РФ // Современный юрист.— 2019.— № 3.— C. 71-84.

15. Черничкина Г.Н. Лицензионный договор: теория и практика его применения // Модернизация гражданско-правого регулирования договорных отношений. Сборник научных статей / Отв. ред. Л.А. Аксенчук.—М.: РАП, 2014.-С. 285-296.

16. Черничкина Г.Н. Функции института лицензионного договора в имущественных отношениях по законодательству Российской Федерации / Г.Н. Черничкина // Имущественные отношения в Российской Федерации. — 2018. — № 7.—C. 72-82.

( ) Миронова Александра Игоревна ( alexsandra_mironova@mail.ru ).

Журнал «Современная наука: актуальные проблемы теории и практики»

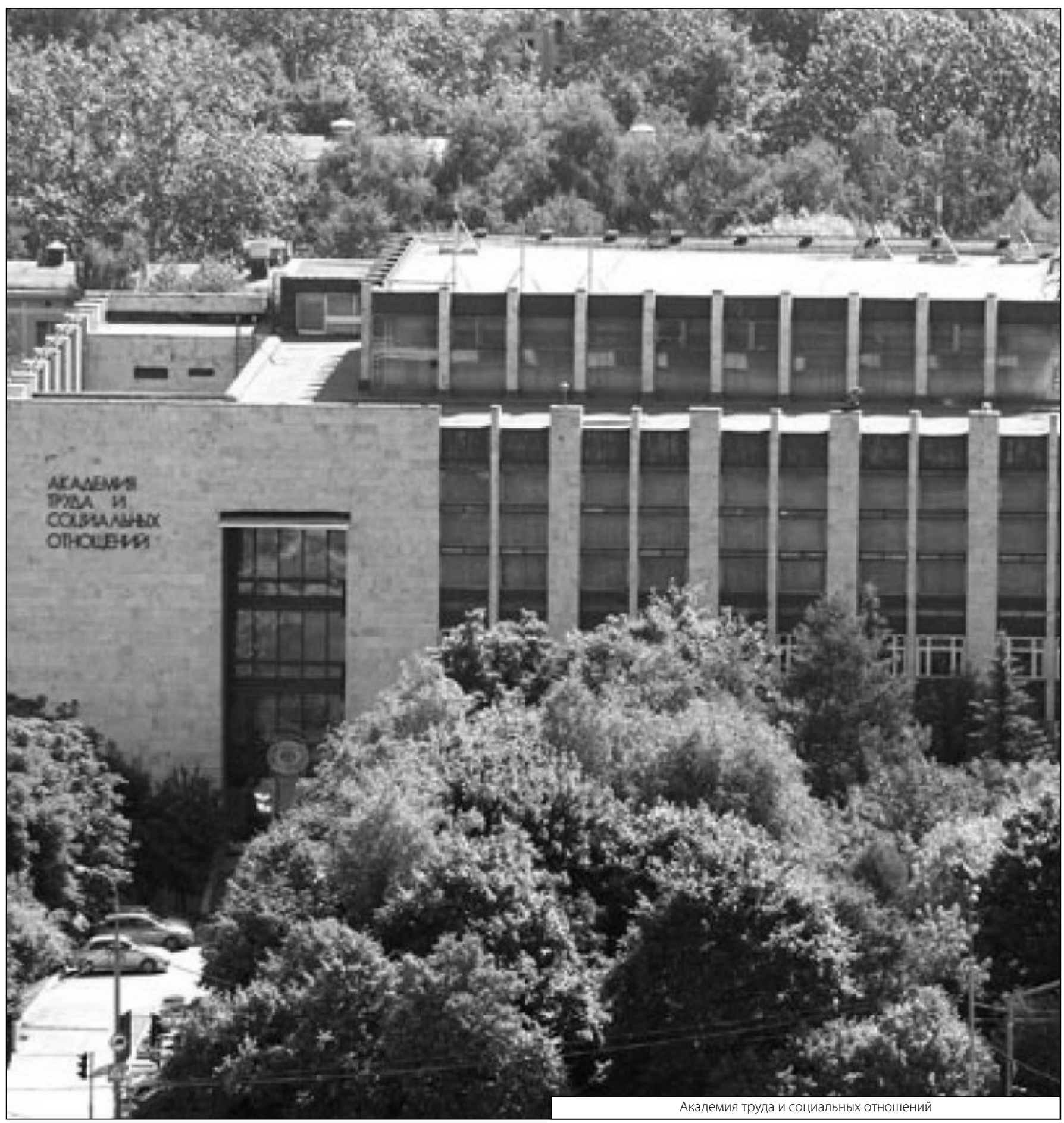

